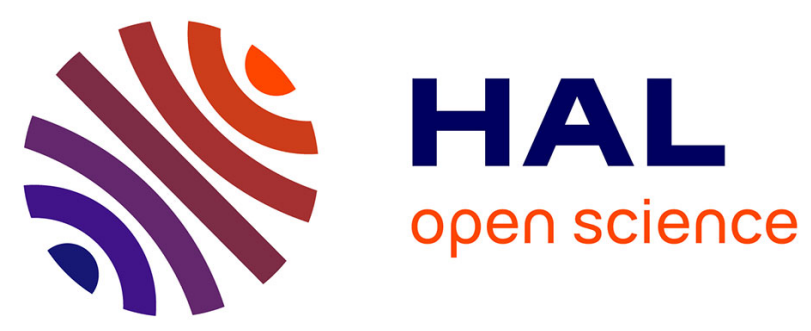

\title{
Doppler sonography of cerebral blood flow for early prognostication after out-of-hospital cardiac arrest DOTAC study
}

Sonia Rafi, Jean-Marc Tadié, Arnaud Gagouin, Guillaume Leurent, Marc Bedossa, Yves Le Tulzo, Adel Maamar

\section{To cite this version:}

Sonia Rafi, Jean-Marc Tadié, Arnaud Gagouin, Guillaume Leurent, Marc Bedossa, et al.. Doppler sonography of cerebral blood flow for early prognostication after out-of-hospital cardiac arrest DOTAC study. Resuscitation, 2019, 141, pp.188-194. 10.1016/j.resuscitation.2019.05.024 • hal-02150347

\section{HAL Id: hal-02150347 \\ https://hal-univ-rennes1.archives-ouvertes.fr/hal-02150347}

Submitted on 2 Jul 2019

HAL is a multi-disciplinary open access archive for the deposit and dissemination of scientific research documents, whether they are published or not. The documents may come from teaching and research institutions in France or abroad, or from public or private research centers.
L'archive ouverte pluridisciplinaire HAL, est destinée au dépôt et à la diffusion de documents scientifiques de niveau recherche, publiés ou non, émanant des établissements d'enseignement et de recherche français ou étrangers, des laboratoires publics ou privés. 


\section{Title of the paper}

Doppler sonography of cerebral blood flow for early prognostication after out-of-hospital cardiac arrest: DOTAC study

\section{Name/affiliations of the authors/contact information}

\section{RAFI Sonia, M.D,}

Service des Maladies Infectieuses et Réanimation Médicale Hôpital Pontchaillou, CHU Rennes 2 rue Henri Le Guilloux 35033 Rennes Cedex

$\underline{\text { Sonia.RAFI@chu-rennes.fr }}$

TADIE Jean-marc, M.D, PhD, Service des Maladies Infectieuses et Réanimation Médicale U1236-MICMAC

Equipe Infectiologie CIC-Inserm-1414 Hôpital Pontchaillou, CHU Rennes 2 rue Henri Le Guilloux 35033 Rennes Cedex

Jeanmarc.TADIE@chu-rennes.fr

\section{GAGOUIN Arnaud, M.D,}

Service des Maladies Infectieuses et Réanimation Médicale

Responsable Equipe Infectiologie CIC-Inserm-1414 Hôpital Pontchaillou, CHU Rennes 2 rue Henri Le Guilloux 35033 Rennes Cedex arnaud.gacouin@chu-rennes.fr

\section{LEURENT Guillaume, M.D,}

Service de Cardiologie et maladies cardiovasculaires Hôpital Pontchaillou, CHU Rennes 2 rue Henri Le Guilloux 35033 Rennes Cedex

Guillaume.LEURENT@chu-rennes.fr

BEDOSSA Marc, M.D,

Service de Cardiologie et maladies cardiovasculaires Hôpital Pontchaillou, CHU Rennes 2 rue Henri Le Guilloux 35033 Rennes Cedex

Marc.Bedossa@chu-rennes.fr

LE TULZO Yves, M.D, PhD, Head of Department, Service des Maladies Infectieuses et Réanimation Médicale Responsable Equipe Infectiologie CIC-Inserm-1414 Hôpital Pontchaillou, CHU Rennes 2 rue Henri Le Guilloux 35033 Rennes Cedex

yves.le.tulzo@chu-rennes.fr

MAAMAR Adel, M.D,

Service des Maladies Infectieuses et Réanimation Médicale Hôpital Pontchaillou, CHU Rennes 2 rue Henri Le Guilloux 35033 Rennes Cedex Adel.MAAMAR@chu-rennes.fr

\section{Corresponding author}

Sonia RAFI, M.D,

Réanimation Médicale Service des Maladies Infectieuses et Réanimation Médicale

Hôpital Pontchaillou, CHU Rennes 2 rue Henri Le Guilloux 35033 Rennes Cedex tel 0299284248

Fax 0299284164

Email: Sonia.RAFI@chu-rennes.fr

\footnotetext{
$\underline{\text { Abstract }}$

Aim: To assess the neurological prognosis of comatose survivors of cardiac arrest by early transcranial Doppler sonography (TCD).

Methods: This was a prospective study performed between May 2016 and October 2017 in a medical intensive care unit (ICU) and a cardiac ICU of a university teaching hospital.

All patients older than 18 years who were successfully resuscitated from an out-of-hospital cardiac arrest (OHCA) with persistent coma after the return of spontaneous circulation (ROSC) were eligible. We excluded patients for whom OHCA was associated with traumatic brain injury, no possibility of TCD measurements, or who were dead before establishing the neurological prognosis.
} 
We measured the pulsatility index (PI) and diastolic flow velocity (DFV) of the right and left middle cerebral arteries within $12 \mathrm{~h}$ after ICU admission. The lowest DFV and highest PI values were used for the statistical analysis. The neurological outcome at hospital discharge was evaluated by the cerebral performance category.

Results: Forty-two patients were included in the final analysis: 15 had good and 27 poor neurological outcomes. The PI was higher in the poor outcome $(1.49 v s .1 .12, \mathrm{p}=0.01)$ than good outcome group and the DFV was lower in the poor outcome group $\left(17.3 \mathrm{~cm} . \mathrm{s}^{-1}\right.$ vs. 26.0 $\left.\mathrm{cm} . \mathrm{s}^{-1} ; \mathrm{p}=0.01\right)$.

Conclusion: Data provided by early TCD after ROSC are associated with neurological outcome. The use of TCD could help guide interventions to improve cerebral perfusion after ROSC in patients resuscitated from OHCA.

Keywords:Out-of-hospital cardiac arrest, transcranial Doppler sonography, cerebrovascular circulation, prognosis.

\section{Introduction}

Out-of-hospital cardiac arrest (OHCA) is a major cause of death and disability, with an incidence rate of 38 to 55 OHCA per 100,000 person-years worldwide (1). Despite recent improvements in the management of OHCA, the survival rate at hospital discharge is still below $10 \%$ (2). Two types of events have been shown to be responsible for the death of patients who survive the initial phase of prehospital care: early reperfusion syndrome, which can induce a refractory state of shock, with death within the first $24 \mathrm{~h}$ following admission, and delayed death induced by neurological impairment (3). A retrospective analysis found that more than $60 \%$ of such patients died due to neurological injury (4). Neurological injury is not only the result of the anoxic period of cardiac arrest, but can also be exacerbated during the postresuscitation phase due to modifications in cerebral blood flow $(\mathrm{CBF})$.

Transcranial Doppler sonography (TCD) is a non-invasive bedside technique that uses ultrasound to measure cerebrovascular haemodynamics (5). The transtemporal measurement of the middle cerebral artery (MCA) pulsatility index (PI) provides a surrogate of cerebral perfusion by recording the velocity of red blood cells circulating in this vessel (6). A higher PI is induced by an increase in downstream vascular resistance (7). TCD is not currently part of the algorithm recommended in the neurological prognosis strategy for comatose survivors of cardiac arrest (8). 
Based on the hypothesis that impaired $\mathrm{CBF}$ in the hours following an OHCA is a marker of ongoing cerebral injury, we assessed the relationship between CBF observed by early TCD examination and neurological outcome at hospital discharge.

\section{Methods}

Study design

This prospective observational study was conducted between May 2016 and October 2017 in the medical intensive care unit (ICU) and cardiac ICU of a university teaching hospital. The hospital's ethical committee approved this study (no. 16.34). The ethical committee waived informed consent, as TCD is considered to be observational.

\section{Patient eligibility}

All adult patients that were successfully resuscitated from an OHCA with persistent coma after the return of spontaneous circulation (ROSC) were eligible. Exclusion criteria were associated traumatic brain injury, the inability to perform TCD because of the absence of an acoustic window or because $>12 \mathrm{~h}$ had passed since admission, and death from refractory shock within the first $72 \mathrm{~h}$, prior to neurological assessment.

\section{OHCA management}

All patients were managed upon admission based on recommendations and received continuous administration of intravenous midazolam and morphine with the objective of attaining a Richmond Assessment Sedation Scale (RASS) of minus five (2,9). Such sedation was maintained for $24 \mathrm{~h}$ or more if there was any reason for maintaining deep sedation, especially in cases of severe acute respiratory distress syndrome. All patients received targeted temperature management during the first $24 \mathrm{~h}$ with an objective of $36^{\circ} \mathrm{C}(10)$. Arterial line placement for all patients allowed continuous monitoring of arterial pressure. A coronary 
angiogram, followed by percutaneous coronary intervention, was performed if the patient's attending physician deemed it necessary.

Neuroprotective measures to prevent secondary cerebral injury of systemic origin were implemented (11). Neither department performed invasive monitoring of intracranial pressure.

\section{Data collection and TCD measurements}

The following parameters were recorded for each eligible patient upon admission: age, gender, mechanism of cardiac arrest (asystole, ventricular fibrillation, pulseless electrical activity), and the time interval between cardiac arrest and resuscitation manoeuvres (no flow), the start of resuscitation manoeuvres and ROSC (low flow), and ROSC and TCD examination.

TCD measurements were performed within $12 \mathrm{~h}$ after ICU admission using a 5-MHz probe for all patients (Philips Healthcare ${ }^{\mathrm{TM}}, \mathrm{CX} 50$ ). We measured systolic flow velocity (SFV), diastolic flow velocity (DFV), mean flow velocity (MFV), and PI of the MCA of each patient for both sides. The PI is a parameter used to assess pulsatility and is defined as the difference between maximum and minimum flow velocity as follows: $\mathrm{PI}=(\mathrm{SFV}-\mathrm{DFV}) / \mathrm{MFV}(6)$. Two trained operators performed all measurements.

We recorded parameters that can influence TCD values during measurement (7): the arterial partial pressure of carbon dioxide $(\mathrm{mmHg})$; mean, systolic, and diastolic blood pressure $(\mathrm{mmHg})$; heart rate; core temperature $\left({ }^{\circ} \mathrm{C}\right)$; haemoglobin level $\left(\mathrm{g} \cdot \mathrm{dl}^{-1}\right)$; and treatment with vasopressors (i.e., epinephrine and/or norepinephrine) at any dose. Serum lactate levels and oxygen partial pressure during the TCD measurements were also measured. If one or more of the biological parameters were not recorded concurrently with the Doppler measurements, the results of the parameter(s) measured closest to the time of the TCD were collected. 
The neurological outcome at hospital discharge was evaluated according to the Pittsburgh Cerebral Performance Category (CPC) scale $(12,13)$ by two independent intensivists blinded to the TCD values. If there was a discrepancy, a third intensivist was asked to decide and validate the final result.

Neurological outcomes were divided into good and poor. A good neurological outcome was defined as a CPC of 1 (good recovery) or 2 (moderate disability). A poor neurological outcome was defined as a CPC of 3 (severe disability), 4 (vegetative state), or 5 (death due to a comatose state or brain death) $(3,4)$. Patients who died before that neurological evaluation was possible were excluded from the analysis, as no neurological evaluation could be performed on sedated patients.

The N20 response to early-latency evoked potentials was sought in accordance with the recommended algorithm for determining the neurological prognosis of comatose survivors of a cardiac arrest (8) and a decision to withdraw and withhold life-sustaining healthcare was collectively made after a multimodal evaluation according to this algorithm and blinded to the TCD results.

\section{Statistical analysis}

A minimum sample of 20 patients for each group was calculated to detect a difference of 0.5 between PI values of each group with a power of 0.8 and an $\alpha$ risk $<0.05$ between patients with good and poor neurologic outcomes (22).

Continuous variables are expressed as medians (interquartile range) and categorical variables as numbers (\%). The Mann-Whitney U-test or Fisher's exact tests were applied, as appropriate, for comparisons between groups. Statistical analyses were performed using Statview 5.0 (SAS Institute Inc., Cary, NC). A p-value $<0.05$ was considered significant. 


\section{Results}

\section{Study population}

During the study period, 88 cardiac-arrest patients resuscitated with ROSC were screened, 36 with in-hospital cardiac arrest and 52 with OHCA (Figure 1). Among the 52 patients with OHCA, $10(19.3 \%)$ were excluded (two because of the absence of an acoustic window at TCD examination, five because of death before neurological evaluation, and three because $>12 \mathrm{~h}$ had passed since admission). Finally, 42 patients (80.7\%) met the eligibility criteria. The demographic characteristics of the study population are summarized in Table 1. Among these 42 patients, $15(35.7 \%)$ had a good neurological outcome ( 11 with CPC $=1$ and four with CPC $=2$ ), and $27(64.3 \%$ ) had a poor neurological outcome (five with $\mathrm{CPC}=3 ; 11$ with $\mathrm{CPC}=4$; and 11 with $\mathrm{CPC}=5$ ) at discharge.

The baseline characteristics, including demographics and haemodynamic parameters did not differ between the good and the poor neurological outcome groups (Table 2).

\section{Poor neurological outcome}

Eleven $(26 \%)$ patients died before $72 \mathrm{~h}$ from neurological causes and were categorized in the poor outcome group. The N20 response was sought for five patients, including a bilateral absence for four. Those patients with a bilaterally absent N20 response died within the first 72 $\mathrm{h}$ after withdrawal of life-sustaining therapies. One had an intact N20 response but multiple comorbidities, including amyotrophic lateral sclerosis, so that the decision to withdraw lifesustaining therapies was made at $72 \mathrm{~h}$. Among the six others, five were in a state of clinical brain death with persistent coma, the absence of brainstem reflexes, and the absence of a breathing drive during apnea, apart from any residual sedation test. The last had a CPC score of 4 . Life-sustaining therapies were withdrawn at $72 \mathrm{~h}$ for these six patients. 
Of note, five patients $(9.6 \%)$ died prematurely from multiple organ failure while they were still sedated without neurological evaluation and consequently excluded from the final analysis. These patients had TCD values within the normal range with a median IP of $1.16(0.92-1.4)$ and median DFV of $30.3 \mathrm{~cm} \cdot \mathrm{s}^{-1}(18.9-41.7)$.

\section{TCD measurements}

TCD was performed after admission in the ICU. SFV, DFV, and MFV were recorded. The PI was automatically calculated by the ultrasound software as follows: (SFV- DFV)/MFV. The median time for TCD measurement after ROSC was 330 min (249-491) for the good-outcome group and $303 \min (26-464)$ for the poor-outcome group $(\mathrm{p}=0.93)$. The TCD values were significantly different depending on the neurological outcome (Table 2). The PI was higher in the poor-outcome $(1.49$ vs. $1.12, \mathrm{p}=0.01)$ than good-outcome group and the DFV was lower in the poor outcome group $\left(17.3 \mathrm{~cm} . \mathrm{s}^{-1} v s .26 .0 \mathrm{~cm} \cdot \mathrm{s}^{-1} ; \mathrm{p}=0.01\right)$.

\section{Discussion}

We found that patients with poor neurological outcomes after OHCA had a lower DFV and higher PI at admission than patients with good neurological outcomes, despite no differences in systemic arterial pressure.

Various studies have provided conflicting results concerning the association between initial TCD values and neurological outcome. Wessels et al. (15) performed serial TCD examinations on various vessels (anterior, middle, and posterior cerebral arteries) during the first $72 \mathrm{~h}$ of hospitalization in 39 patients with cardiorespiratory arrest. Of the 39 patients, 22 died or had neurological outcomes considered to be unfavourable. By the fourth hour, the peak systolic and diastolic velocities in the middle cerebral artery were lower in non-survivors than survivors. However, patients with unfavourable neurological outcomes appeared to have higher resistance indexes, even if the result did not reach the significance. To date, only one study has shown a 
significant association between values measured by TCD examination and neurological evolution measured by the CPC score. Interestingly, the TCD examination was performed early in the course of ROSC, at three time points: before targeted temperature management, between 12 and $24 \mathrm{~h}$, and between 24 and $48 \mathrm{~h}$ during the targeted temperature management phase. However, the study population consisted exclusively of children (16).

The main difference between these studies and ours is that we excluded patients who died prematurely from multi-organ failure without neurological evaluation. Of note, patients who died prematurely in our study had normal TCD values.

Concerning haemodynamic parameters, we found no differences in systolic, diastolic, or mean blood pressure (MBP) between the good-outcome and poor-outcome groups. In particular, only the MBP value did not differentiate patients whose cerebral perfusion was altered, contrary to the TCD parameters. We did not find a statistical difference in arterial blood pressure between our two groups, although we cannot rule out a clinically relevant difference due to the small sample.

The neurological outcome depends on the prompt restoration of systemic circulation and oxygenation after ROSC to meet cerebral oxygen demands $(16,17)$. These studies suggest that $\mathrm{CBF}$ and the MCA pulsatility index at the early ROSC phase may correlate with neurological outcome. The high PI associated with decreased DFV observed in our study favours an increase in vascular resistance at the acute phase after a resuscitated cardiac arrest, as observed by other authors $(18,19)$. During the post-resuscitation phase after ROSC, ischaemia-reperfusion phenomena induce disturbances of CBF. Recent studies have described the course of DSC after ROSC, which can be divided into three periods $(20,21)$. Immediately after ROSC, CBF is characterised by early hyperaemia for $30 \mathrm{~min}$, followed by a hypoperfusion phase of 6 to $12 \mathrm{~h}$. The third period shows restoration of normal CBF, increased CBF $(22,23)$, or persistent 
decreased CBF from 12 to $72 \mathrm{~h}$ after ROSC (22-24). There are several hypotheses that can explain such $\mathrm{CBF}$ abnormalities, including the secretion of endothelin, a potent vasoconstrictor that may be involved in the modification of cerebral vascular tone (25). Until recently, it was assumed that under normal circumstances, autoregulation maintains a constant CBF and changes in mean blood pressure within a range of 50-150 $\mathrm{mm} \mathrm{Hg}$ have a minor influence on CBF $(26,27)$. However, recent studies have shown that autoregulation maintains CBF within a smaller range above baseline MBP $(20,28)$. Several studies showed that cerebral autoregulation is preserved in the aftermath of cardiac arrest $(18,29)$. In contrast, several lines of evidence have demonstrated that there is no regulation of CBF. For example, Sundgreen et al. (30) showed that cerebral autoregulation was either absent or altered, with the curve shifted to the right, in most of a series of 18 patients. Therefore, systemic arterial pressure may not allow prompt monitoring in brain perfusion. In the event of impairment of cerebral autoregulation, minimal variations in $\mathrm{MBP}$ are likely to alter $\mathrm{CBF}$ without being detectable by conventional monitoring, including continuous monitoring of intracranial pressure.

Moreover, it may be important to determine whether TCD values at an early stage after ROSC are predictive of neurological outcome (19,31). Impaired DFV and increased PI are considered to be pathological in severe traumatic brain injury (32) and are used to guide therapy to restore adequate cerebral perfusion. Therefore, normalization of TCD values at early stages of ROSC may represent an interesting approach to improve neurological outcome after OHCA. Heradstveit et al. showed the presence of ischaemic lesions at $24 \mathrm{~h}$ in these patients by magnetic resonance imaging with diffusion sequences (33). The final objective would be to improve cerebral perfusion by optimizing local factors (parameters of mechanical ventilation, metabolic coupling, patient posture), as well as systemic factors (stroke volume, myocardial contractility).

Only a small number of patients were excluded because of the impossibility of interpreting the TCD (no window or the passage of too much time after admission). This confirms the feasibility 
of the TCD examination in common practice in ICUs during the acute phase after a cardiac arrest. The other exclusions consisted of five patients $(9.6 \%)$ who died prematurely from multiple organ failure while they were still sedated and could not be neurologically evaluated. This finding is in agreement with the literature, which shows that approximately $10 \%$ of patients resuscitated from an OHCA early die of multiple organ failure (4). Such early death should not be considered for the neurological prognosis because the outcome could have been favourable if the patients had survived the initial acute circulatory failure.

Our study had some limitations. First, TCD does not directly measure CBF. Velocities may reflect $\mathrm{CBF}$, provided there is no variation in the calibre of the insonated vessel. The relationship between TCD velocities and CBF are complex and involve many parameters, such as vasoreactivity to hypoxia and hypercapnia, the effect of neuronal metabolism, and the effect of the autonomic nervous system $(34,35)$.

Second, the patients came from two different settings of the same hospital, the results of which merit confirmation on a larger scale. Nevertheless, the management of comatose survivor patients from an OHCA in the ICU is standardized due to the standard edition of international recommendations on the subject (36). Our population was small and heterogenous and a larger study is needed to perform multivariate analyses to identify PI or DVF as independent factors of a poor or good outcome. Furthermore, a larger sample would contribute to a better understanding of the pathophysiology of post-anoxic encephalopathy by providing data from patients with cardiac versus non-cardiac causes of OHCA.

Third, we acknowledge a potential bias given the low interrater reliability of some TCD measurements. All TCD measurements in our study were thus performed by only two trained operators to mitigate such bias. 
Only one study has had a larger number of patients than ours; however, it did not show any relationship between TCD values and neurological outcome. This may be because the TCD measurements were performed later, i.e., at $48 \mathrm{~h}, 72 \mathrm{~h}$, and 7 days after ROSC, including on patients who died before neurological evaluation (31).

\section{Conclusion}

Data provided by early TCD examination after ROSC are associated with neurological outcome. The use of TCD could help guide interventions to improve cerebral perfusion after ROSC in patients resuscitated from OHCA.

\section{Conflicts of interest}

None

\section{Conflict of Interest Statement}

All authors have made contribution to the conception of the study, acquisition of data, and analysis of data, and state the absence of conflict of interest in their contribution to this study

\section{Acknowledgements}

The authors would like to thank the ICU staff and cardiology department for their participation in the transcranial Doppler measurements and their involvement in allowing the inclusion of patients admitted after OHCA. 


\section{References}

1. Gräsner J-T, Lefering R, Koster RW, Masterson S, Böttiger BW, Herlitz J, et al. EuReCa ONE27 Nations, ONE Europe, ONE Registry. Resuscitation. august 2016;105:188- 95.

2. Bossaert LL, Perkins GD, Askitopoulou H, Raffay VI, Greif R, Haywood KL, et al. European Resuscitation Council Guidelines for Resuscitation 2015. Resuscitation. oct 2015;95:302- 11.

3. Mongardon N, Dumas F, Ricome S, Grimaldi D, Hissem T, Pène F, et al. Postcardiac arrest syndrome: from immediate resuscitation to long-term outcome. Ann Intensive Care. 2011;1(1):45.

4. Laver S, Farrow C, Turner D, Nolan J. Mode of death after admission to an intensive care unit following cardiac arrest. Intensive Care Med. nov 2004;30(11):2126- 8.

5. Saqqur M, Zygun D, Demchuk A. Role of transcranial Doppler in neurocritical care: Crit Care Med. may 2007;35(Suppl):S216- 23.

6. Geeraerts T, Ract C, Duranteau J, Vigué B. Le doppler transcrânien en neurochirurgie. Neurochirurgie. 2008;54(6):731- 8.

7. Vigue B, Tazarourte K, Geeraerts T, Ract C, Duranteau J. Le doppler transcrânien en réanimation. Réanimation. oct 2007;16(6):538- 45.

8. Sandroni C, Cariou A, Cavallaro F, Cronberg T, Friberg H, Hoedemaekers C, et al. Prognostication in comatose survivors of cardiac arrest: An advisory statement from the European Resuscitation Council and the European Society of Intensive Care Medicine. Intensive Care Med. dec 2014;40(12):1816- 31.

9. Sessler CN, Gosnell MS, Grap MJ, Brophy GM, O’Neal PV, Keane KA, et al. The Richmond AgitationSedation Scale: Validity and Reliability in Adult Intensive Care Unit Patients. Am J Respir Crit Care Med. nov 2002;166(10):1338- 44.

10. Nielsen N, Wetterslev J, Cronberg T, Erlinge D, Gasche Y, Hassager C, et al. Targeted Temperature Management at $33^{\circ} \mathrm{C}$ versus $36^{\circ} \mathrm{C}$ after Cardiac Arrest. N Engl J Med. 2013;369(23):2197- 206.

11. Moeschler O, Boulard G, Ravussin P. Concept d'agression cérébrale secondaire d'origine systémique (ACSOS). In: Annales francaises d'anesthesie et de reanimation. Elsevier; 1995 p. 114-121.

12. Gehlbach SH, Williams WA, Perry LD, Freeman JI, Langone JJ, Peta LV, et al. Nicotine absorption by workers harvesting green tobacco. The Lancet. 1975;305(7905):478-480.

13. Hazinski MSN, Nadkarni V, Kloeck W, Kramer E, Becker L, Robertson C, et al. Recommended guidelines for reviewing, reporting, and conducting research on in-hospital resuscitation: the in-hospital 'Utstein style'.

14. Campbell MJ, Julious SA, Altman DG. Estimating sample sizes for binary, ordered categorical, and continuous outcomes in two group comparisons. BMJ. oct 1995;311(7013):1145 - 8.

15. Wessels T, Harrer JU, Jacke C, Janssens U, Kl?tzsch C. The prognostic value of early transcranial doppler ultrasound following cardiopulmonary resuscitation. Ultrasound Med Biol. déc 2006;32(12):1845 - 51.

16. Lin J-J, Hsia S-H, Wang H-S, Chiang M-C, Lin K-L. Transcranial Doppler ultrasound in therapeutic hypothermia for children after resuscitation. Resuscitation. 2015;89:182- 7.

17. Álvarez-Fernández JA, Pérez-Quintero R. Use of transcranial Doppler ultrasound in the management of post-cardiac arrest syndrome. Resuscitation. 2009;80(11):1321 - 2.

18. Buunk G, Van der Hoeven JG, Meinders AE, Frölich M. Cerebral vasoconstriction in comatose patients resuscitated from a cardiac arrest? Intensive Care Med. 1996;22(11):1191-1196.

19. Lemiale V, Huet O, Vigué B, Mathonnet A, Spaulding C, Mira J-P, et al. Changes in cerebral blood flow and oxygen extraction during post-resuscitation syndrome. Resuscitation. 2008;76(1):17- 24.

20. van den Brule JMD, van der Hoeven JG, Hoedemaekers CWE. Cerebral Perfusion and Cerebral Autoregulation after Cardiac Arrest. BioMed Res Int 2018;2018:1 - 5.

21. Iordanova B, Li L, Clark RSB, Manole MD. Alterations in Cerebral Blood Flow after Resuscitation from Cardiac Arrest. Front Pediatr 2017

22. Pollock JM, Whitlow CT, Deibler AR, Tan H, Burdette JH, Kraft RA, et al. Anoxic Injury-Associated Cerebral Hyperperfusion Identified with Arterial Spin-Labeled MR Imaging. Am J Neuroradiol . 2008;29(7):1302- 7.

23. Iida K, Satoh $\mathrm{H}, \quad$ Arita $\quad$ K.

Delayed_hyperemia_causing_intracranial_hypertension_after_cardiopulmonary.html. Crit Care Med. 1997;25:971- 6 .

24. Buunk G, Meinders AE. Cerebral vasoconstriction in comatose patients resuscitated from a cardiac arrest?

:6.

25. Bacic F, Uematsu S, McCarron RM, Spatz M. Secretion of immunoreactive endothelin-1 by capillary and microvascular endothelium of human brain. Neurochem Res. 1992;17(7):699-702.

26. Aaslid R, Lindegaard KF, Sorteberg W, Nornes H. Cerebral autoregulation dynamics in humans. Stroke $1989 ; 20(1): 45-52$.

27. Lassen NA. Cerebral Blood Flow and Oxygen Consumption in Man. Physiol Rev .1959];39(2):183- 238. 
28. Tan CO. Defining the characteristic relationship between arterial pressure and cerebral flow. J Appl Physiol 2012;113(8):1194- 200.

29. Bisschops LLA, Hoedemaekers CWE, Simons KS, van der Hoeven JG. Preserved metabolic coupling and cerebrovascular reactivity during mild hypothermia after cardiac arrest*: Crit Care Med. 2010;38(7):1542- 7. 30. Sundgreen C, Larsen FS, Herzog TM, Knudsen GM, Boesgaard S, Aldershvile J. Autoregulation of cerebral blood flow in patients resuscitated from cardiac arrest. Stroke. 2001;32(1):128-132.

31. Doepp (Connolly) F, Reitemeier J, Storm C, Hasper D, Schreiber SJ. Duplex sonography of cerebral blood flow after cardiac arrest—A prospective observational study. Resuscitation. avr 2014;85(4):516- 21.

32. Ract C, Le Moigno S, Bruder N, Vigué B. Transcranial Doppler ultrasound goal-directed therapy for the early management of severe traumatic brain injury. Intensive Care Med.2007;33(4):645- 51.

33. Heradstveit BE, Larsson E-M, Skeidsvoll H, Hammersborg S-M, Wentzel-Larsen T, Guttormsen AB, et al. Repeated magnetic resonance imaging and cerebral performance after cardiac arrest-A pilot study. Resuscitation. 2011;82(5):549- 55.

34. Willie CK, Tzeng Y-C, Fisher JA, Ainslie PN. Integrative regulation of human brain blood flow: Integrative regulation of human brain blood flow. J Physiol 2014 ;592(5):841 - 59.

35. Hoedemaekers CW, Ainslie PN, Hinssen S, Aries MJ, Bisschops LL, Hofmeijer J, et al. Low cerebral blood flow after cardiac arrest is not associated with anaerobic cerebral metabolism. Resuscitation 2017; $120: 45-50$.

36. Nolan JP, Soar J, Cariou A, Cronberg T, Moulaert VRM, Deakin CD, et al. European Resuscitation Council and European Society of Intensive Care Medicine Guidelines for Post-resuscitation Care 2015. Resuscitation2015;95:202- 22. 
Figure 1. Flow chart of patients study

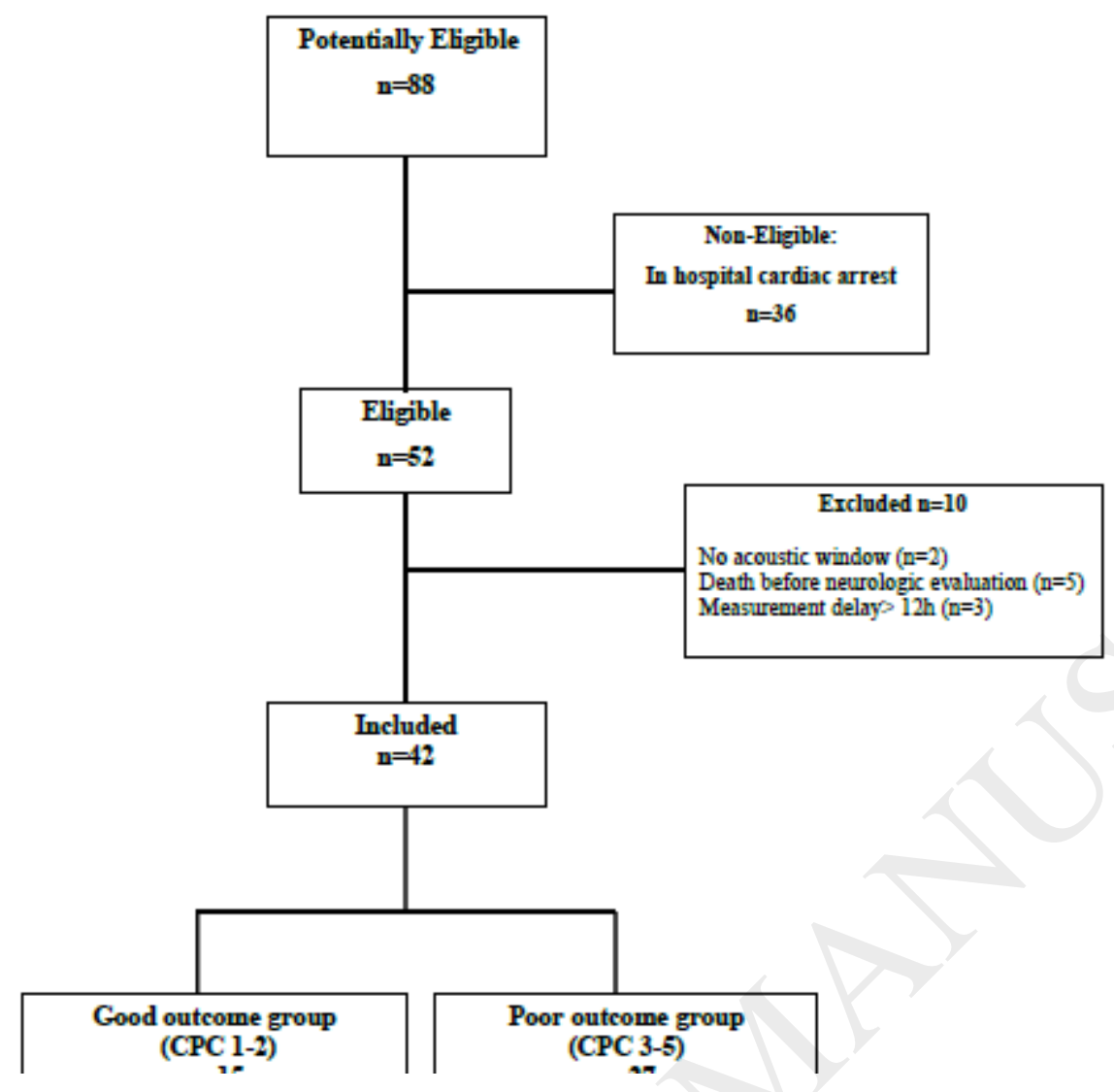


Table1. Baseline characteristics

\begin{tabular}{|c|c|}
\hline Variables & $n=42$ \\
\hline $\begin{array}{l}\text { Gender } \\
\text { Men, n (\%) } \\
\text { Women, n }(\%)\end{array}$ & $\begin{array}{ll}32 & (76.2) \\
10 & (23.8)\end{array}$ \\
\hline $\begin{array}{l}\text { Mechanism of OHCA } \\
\text { Asystole, n (\%) } \\
\text { Ventricular fibrillation, n (\%) }\end{array}$ & $\begin{array}{ll}25 & (59.5) \\
17 & (40.5)\end{array}$ \\
\hline Coronarography, n (\%) & $13 \quad(30.9)$ \\
\hline Revascularization, n (\%) & $10 \quad(23.8)$ \\
\hline $\begin{array}{l}\text { Vasopressors } \\
\text { Adrenaline, n (\%) } \\
\text { Noradrenaline, n (\%) } \\
\text { No catecholamine, n }(\%)\end{array}$ & $\begin{array}{ll}4 & (9.5) \\
7 & (73.8) \\
31 & (16.7)\end{array}$ \\
\hline $\begin{array}{l}\text { Setting } \\
\text { Medical intensive unit, n (\%) } \\
\text { Cardiac intensive unit, n (\%) }\end{array}$ & $\begin{array}{ll}34 & (81.0) \\
8 & (19.0)\end{array}$ \\
\hline Age (years) & $61 \quad(47-71)$ \\
\hline $\begin{array}{l}\text { Parameters of ROSC } \\
\text { No flow duration }(\mathrm{mn}) \\
\text { Low flow duration }(\mathrm{mn}) \\
\text { EtCO2 post ROSC }(\mathrm{mmHg})\end{array}$ & $\begin{array}{ll}2.5 & (0-5) \\
21 & (10-27) \\
39 & (33-45)\end{array}$ \\
\hline
\end{tabular}

Data are presented as number (\%) or median (interquartile range). OHCA = Out-of-Hospital Cardiac Arrest, ROSC $=$ Return of Spontaneous Circulation, EtCO2 $=$ Expired carbon dioxide. 
Table 2. Characteristics of patients by neurologic outcomes

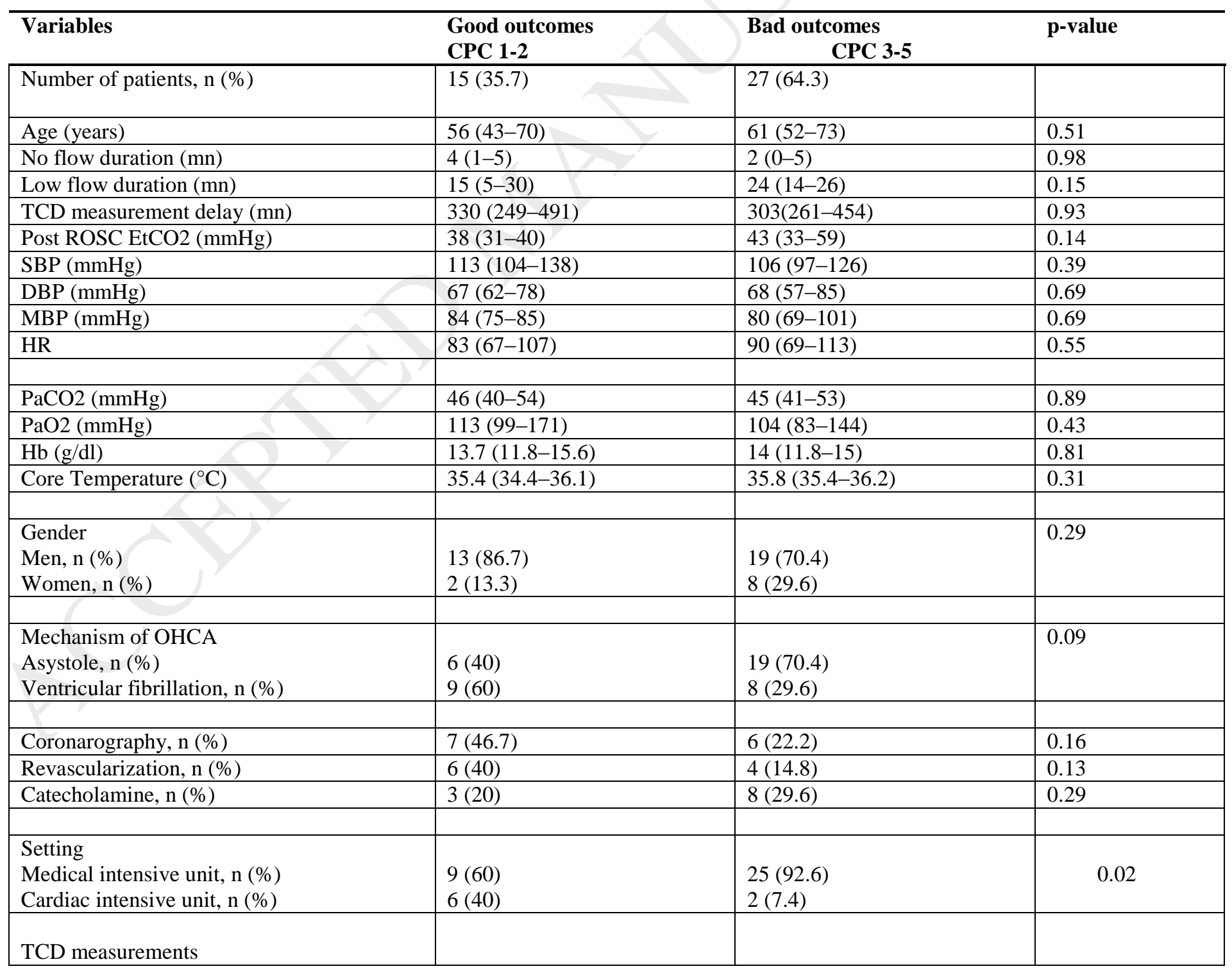




\begin{tabular}{|l|l|l|l|}
\hline Right Systolic Flow Velocity $\left(\mathrm{cm} . \mathrm{s}^{-1}\right)$ & $67(53.1-96.6)$ & $71.5(59.4-90.2)$ & 0.93 \\
Left Systolic Flow Velocity $\left(\mathrm{cm}^{-1}\right)$ & $69.1(58-83.2)$ & $65(56.7-84.7)$ & 0.90 \\
Right Mean Flow Velocity $\left(\mathrm{cm} . \mathrm{s}^{-1}\right)$ & $42.2(35.2-50)$ & $43.7(27.6-51.7)$ & 0.69 \\
Left Mean Flow Velocity $\left(\mathrm{cm} . \mathrm{s}^{-1}\right)$ & $43.8(35.5-51.2)$ & $38.8(46.4)$ & 0.23 \\
Diastolic Flow Velocity $\left(\mathrm{cm} . \mathrm{s}^{-1}\right)$ & 26 & 17.3 & 0.01 \\
Pulsatility Index & 1.12 & 1.49 & 0.01 \\
\hline
\end{tabular}

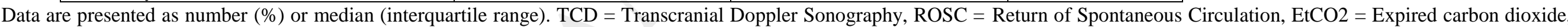

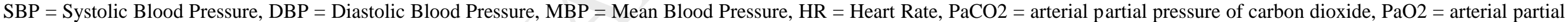
pressure of oxygen, $\mathrm{Hb}=$ Haemoglobin, $\mathrm{OHCA}=$ Out of Hospital Cardiac Arrest. 